\title{
Epidemiology and implications of ocular trauma admitted to hospital in Scotland
}

\author{
Parul Desai, Caroline J MacEwen, Paul Baines, Darwin C Minassian
}

\begin{abstract}
Objectives - To describe the current epidemiology of serious ocular trauma which necessitates admission to hospital so that health and safety strategies for the prevention of ocular injuries and their role within the national health strategy, The Health of the Nation, can be better informed.

Design - A prospective observational study of all patients with ocular trauma admitted to hospital under the care of a consultant ophthalmologist between 1 November 1991 and 31 October 1992.
\end{abstract}

Setting - All ophthalmic departments in Scotland.

Subjects - All patients with ocular trauma admitted to hospital in Scotland. The population of Scotland represented the population at risk of injury.

Measures and main results - Measures included the type and cause of injury, the place where it occurred, and awareness of risk and safety. All ophthalmic departments in Scotland participated and 428 admissions were reported. The home was the most common place for a serious injury to occur $(30.2 \%)$, followed by the workplace $(19.6 \%)$ and a sports or leisure facility $(15.8 \%)$. The home was the single most frequent place of injury for the 0-15 year and 65 year and over age groups. Tools or machinery, either at home $(13.9 \%)$ or at work $(10.3 \%)$, were collectively $(24.2 \%)$ the most frequent cause of injury, followed by assault (21.8\%) and sports-related activities (12.5\%). The most frequent type of injury was a blunt injury $(54.4 \%)$. Six per cent $(n=25)$ of all injuries were bilateral. Only $13.2 \%$ of patients were aware of any risk of injury, with $5.6 \%$ aware of any risk at home. When applicable, protective eye wear was only available to $48.6 \%$ of patients and only $19.4 \%$ of these used it

Conclusion - Serious ocular trauma frequently occurs at home and the young and the elderly are particularly at risk. This represents a significant change in the epidemiology of serious ocular trauma and has important implications for prevention. Health and safety strategies specifically aimed at preventing eye injury should now include the home as a high risk environment in addition to the workplace and sports/leisure facilities. The target groups for accident prevention in The Health of the Nation strategy include those at risk of serious ocular trauma with potentially sight threatening sequelae.
Those involved in implementing the national accident prevention strategy should be aware of this, for in this process it is possible that some serious eye injuries may also be prevented.

$(\Im$ Epidemiol Community Health 1996;50:436-441)

Ocular trauma represents a significant workload for ophthalmic services and accounts for about $38 \%$ to $52 \%$ of all new patients presenting as ophthalmic "accident and emergency" cases to hospital. ${ }^{1-4}$ Most of these are minor injuries and it is estimated that only a very small proportion of all injuries (between $0.9 \%$ and $1.8 \%$ ) are of sufficient severity to warrant admission to hospital. ${ }^{15}$ Given that these are not frequent events, few epidemiological data on patients admitted to hospital in this country with ocular injuries are available. There have been few population based studies. Most previous reports have been retrospective and either hospital or occupationally based, concentrating particularly on specific types of injuries or the setting in which the injury took place, and predominantly concerned with minor injuries that pose minimal risk of permanent visual impairment. ${ }^{16-10}$

This study was conducted to provide epidemiological data on the current characteristics of moderate to severe ocular trauma which necessitates admission to hospital. It aimed to inform health and safety strategies on the prevention of serious ocular injuries for the maintenance of eye health and on their role within the national health strategy, The Health of the Nation, which was being developed at this time. The national health strategy had identified accident prevention as a key priority area for the improvement and maintenance of health in the population. ${ }^{11}$

We describe the epidemiology of moderate to severe ocular trauma presenting to the hospital eye service in Scotland, providing injury patterns and characteristics for different patient groups.

\section{Method}

This was a prospective observational study of all patients admitted for ocular trauma under the care of a consultant ophthalmologist in Scotland between 1 November 1991 and 31 October 1992. All patients were followed up until 31 December 1992 or discharge from ophthalmic care, whichever came first. The population at risk of injury during the study period was that of Scotland and was estimated to be about five million in 1991 (data from Information and Statistics Division, National Health Service in Scotland, Edinburgh). 
Table 1 Type of injury (no (row \%)) in relation to age and gender

\begin{tabular}{|c|c|c|c|c|c|c|c|c|c|}
\hline & Blunt & $\begin{array}{l}\text { Penetrating, no } \\
\text { IOFB }\end{array}$ & $\begin{array}{l}\text { Penetrating, } \\
\text { with IOFB }\end{array}$ & Chemical burn & Physical burn & Other & Not recorded & Unknown & All types \\
\hline \multicolumn{10}{|l|}{ Age (y) } \\
\hline $0-4$ & $7(46.70)$ & $5(33.3)$ & $0(0)$ & $1(6.7)$ & - & $2(13.3)$ & - & - & $15(100)$ \\
\hline $5-15$ & $53(67.9)$ & $17(21.8)$ & $4(5.1)$ & - & - & $2(2.6)$ & - & $2(2.6)$ & $78(100)$ \\
\hline $16-24$ & $50(53.8)$ & $29(31.2)$ & $4(4.3)$ & $5(5.4)$ & $1(1.1)$ & $4(4.3)$ & - & - & $93(100)$ \\
\hline $25-64$ & $97(49.0)$ & 39 (19.7) & $20(10.1)$ & $18(9.1)$ & $3(1.5)$ & $15(7.6)$ & $1(0.5)$ & $5(2.5)$ & $198(100)$ \\
\hline $65+$ & $15(60.0)$ & $3(12.0)$ & $1(4.0)$ & $2(8.0)$ & - & $4(16.0)$ & - & - & $25(100)$ \\
\hline Unknown & $5(62.5)$ & - & $1(12.5)$ & $1(12.5)$ & - & - & - & $1(12.5)$ & $8(100)$ \\
\hline All & $227(54.4)$ & $93(22.3)$ & $30(7.2)$ & $27(6.5)$ & $4(1.0)$ & $27(6.5)$ & $1(0.2)$ & $8(1.9)$ & $417(100)$ \\
\hline \multicolumn{10}{|l|}{ Gender } \\
\hline Female & $45(65.2)$ & $15(21.7)$ & - & $2(2.9)$ & $1(1.4)$ & $4(5.8)$ & $1(1.4)$ & $1(1.4)$ & $69(100)$ \\
\hline Male & $181(52.3)$ & $78(22.5)$ & $30(8.7)$ & $25(7.2)$ & $3(0.9)$ & $22(6.4)$ & - & $7(2.0)$ & $346(100)$ \\
\hline Unknown & 1 & - & - & - & - & 1 & - & - & 2 \\
\hline All & $227(54.4)$ & $93(22.3)$ & $30(7.2)$ & $27(6.5)$ & $4(1.0)$ & $27(6.5)$ & $1(0.2)$ & $8(1.9)$ & $417(100)$ \\
\hline
\end{tabular}

IOFB = intraocular foreign body.

Table 2 Place of injury (no (row \%)) in relation to age and gender

\begin{tabular}{|c|c|c|c|c|c|c|c|c|c|c|c|c|}
\hline & $\begin{array}{l}\text { Work - } \\
\text { agricultural }\end{array}$ & $\begin{array}{l}\text { Work - } \\
\text { industrial }\end{array}$ & $\begin{array}{l}\text { Work - } \\
\text { commercial }\end{array}$ & School & Home & $\begin{array}{l}\text { Sports/ } \\
\text { leisure } \\
\text { facility }\end{array}$ & $\begin{array}{l}\text { Car with } \\
\text { seat belt }\end{array}$ & $\begin{array}{l}\text { Car no } \\
\text { seat belt }\end{array}$ & $\begin{array}{l}\text { Pavement } \\
\text { or street }\end{array}$ & Other* & Unknownt & All places \\
\hline \multicolumn{13}{|l|}{ Age (y) } \\
\hline $0-4$ & - & - & - & - & $11(73.3)$ & - & - & - & $1(6.7)$ & $2(13.3)$ & $1(6.7)$ & $15(100)$ \\
\hline $5-15$ & - & - & - & $13(16.7)$ & $36(46.2)$ & $9(11.5)$ & - & - & $8(103)$ & $6(7.7)$ & $6(7.7)$ & $78(100)$ \\
\hline $16-24$ & $2(2.2)$ & $14(15.1)$ & 7 (7.5) & $1(1.1)$ & $17(18.3)$ & $23(24.7)$ & $3(3.2)$ & - & $10(10.8)$ & $7(7.5)$ & $9(9.7)$ & $93(100)$ \\
\hline $25-64$ & $8(4.0)$ & $37(18.7)$ & $12(6.1)$ & $2(1.0)$ & $45(22.7)$ & $32(16.2)$ & $3(1.5)$ & $4(2.0)$ & $14(7.1)$ & $28(14.1)$ & $13(6.6)$ & $198(100)$ \\
\hline $65+$ & - & - & - & - & $15(60.0)$ & - & $1(4.0)$ & - & $4(16.0)$ & $3(12.0)$ & $2(8.0)$ & $25(100)$ \\
\hline Not known & - & - & $2(25.0)$ & - & $2(25.0)$ & $2(25.0)$ & - & - & $1(12.5)$ & - & $1(12.5)$ & $8(100)$ \\
\hline All & $10(2.4)$ & $51(12.2)$ & $21(5.0)$ & $16(3.8)$ & $126(30.2)$ & $66(15.8)$ & $7(1.7)$ & $4(1.0)$ & $38(9.1)$ & $46(11.0)$ & $32(7.7)$ & $417(100)$ \\
\hline \multicolumn{13}{|l|}{ Gender $\ddagger$} \\
\hline Female & - & - & $1(1.4)$ & $3(4.3)$ & $36(52.2)$ & $11(15.9)$ & $2(2.9)$ & - & $4(5.8)$ & $8(11.6)$ & $4(5.8)$ & $88(100)$ \\
\hline Male & $10(2.9)$ & $51(14.7)$ & $19(5.5)$ & $13(3.8)$ & $90(26.0)$ & $55(15.9)$ & $4(1.2)$ & $4(1.2)$ & $34(9.8)$ & $38(11.0)$ & $28(8.1)$ & $346(100)$ \\
\hline Not known & - & - & $1(50.0)$ & - & - & - & $1(50.0)$ & - & - & - & - & $2(100)$ \\
\hline All & $10(2.4)$ & $51(12.2)$ & $21(5.0)$ & $16(3.8)$ & $126(30.2)$ & $66(15.8)$ & $7(1.7)$ & $4(1.0)$ & $38(9.1)$ & $46(11.0)$ & $32(7.7)$ & $417(100)$ \\
\hline
\end{tabular}

*Includes 1 bicycle (no helmet) and 3 motor bikes (with helmet, males); tincludes 21 not recorded. $\ddagger$ Gender data $-\chi^{2}=30.58, \mathrm{df}=10, \mathrm{p}$ value $=<0.001$.

All ophthalmic consultants in Scotland were invited to participate by providing clinical data on all patients admitted under their care with an ocular injury sustained during the study period. Patients with an ocular injury who were referred from another specialty were also included provided that the injury had been sustained during the study period. A consultant ophthalmologist was identified in each ophthalmic department to act as the local coordinator to supervise and facilitate data collection at each centre. Regular feedback on identification, recruitment, and follow up of patients was provided to each centre at three-monthly intervals throughout the study period.

All data were collected on standardised proforma booklets developed specifically for the study. These contained separate proformas for reporting the event (admission of an ocular injury) and details on the process of care provided: the history and clinical assessment of the injury; clinical management on admission; follow up in outpatients; discharge from ophthalmic care and for reporting a tertiary referral at any stage. Data were collected on the demographic characteristics of patients, the type of injury, cause (or activity) of injury, and the place (or setting) in which it was sustained. Information on whether protective eye wear was available and used, whether first aid was administered or not, and awareness of risk of injury, was obtained from the patient on admission. "First aid" for the purposes of this study constituted irrigation of the eye and/or the application of an eye pad. This information was ascertained by direct questioning of the patient in the case of irrigation and on inspection in the case of application of an eye pad. Patients were also asked whether they had been aware of any possible risk of an eye injury associated with the activity they had been pursuing at the time of injury.

Also included in each booklet were instructions for the completion of the proforma together with the definitions used in the study.

At the end of the study period, completeness of reporting of admissions for eye injuries by ophthalmologists was assessed by comparison with routine hospital activity returns for inpatients and day cases to the Department of Health, Scotland (Standard Morbidity Record-1 (SMR-1)) and are reported elsewhere. ${ }^{12}$

The main findings are presented as relative frequency distributions of injury characteristic (type, place, and cause of injury) in relation to age group and sex. These provide the conditional probabilities of an injury displaying the characteristic under consideration, among those injured, allowing comparisons and profiles of injury characteristics in subgroups, defined by age and sex. Incidence rates are reported elsewhere. ${ }^{12}$

\section{Results}

All 18 eligible ophthalmic departments in Scotland providing regular inpatient and out- 
Table 3 Main activity or object causing eye injury (no(row\%)) in relation to age and gender

\begin{tabular}{|c|c|c|c|c|c|c|c|c|c|}
\hline & Assault & $\begin{array}{l}\text { Tools or } \\
\text { machinery } \\
\text { at work }\end{array}$ & $\begin{array}{l}\text { Tools or } \\
\text { machinery } \\
\text { at home }\end{array}$ & Sport & $\begin{array}{l}\text { Chemicals at } \\
\text { work }\end{array}$ & Fall & $\begin{array}{l}\text { Road traffic } \\
\text { accident }\end{array}$ & Other* & All \\
\hline \multicolumn{10}{|l|}{$\operatorname{Age}(y)$} \\
\hline $0-4$ & - & - & $3(20.0)$ & $1(6.7)$ & - & $1(6.7)$ & - & $10(66.7) \dagger$ & $15(100)$ \\
\hline $5-15$ & $13(16.7)$ & $1(1.2)$ & $6(7.7)$ & $14(18)$ & - & $4(5.1)$ & - & $40(51.3) \ddagger$ & $78(100)$ \\
\hline $16-24$ & $22(23.7)$ & $11(11.8)$ & $10(10.8)$ & $16(17.2)$ & $4(4.3)$ & $1(1.1)$ & $5(5.3)$ & $24(25.8)$ & $93(100)$ \\
\hline $25-64$ & $51(25.80)$ & $30(15.1)$ & $33(16.7)$ & $20(10.1)$ & $12(6.1)$ & $8(4.0)$ & $8(4.0)$ & $36(18.2)$ & $198(100)$ \\
\hline $65+$ & $4(16.0)$ & - & $5(20.0)$ & - & - & $11(44.0)$ & $1(4.0)$ & $4(16.0)$ & $25(100)$ \\
\hline Unknown & 1 & 1 & 1 & 1 & 1 & 1 & - & 2 & $8(100)$ \\
\hline All & $91(21.8)$ & $43(10.3)$ & $58(13.9)$ & $52(12.5)$ & $17(4.1)$ & $26(6.2)$ & $14(3.4)$ & $116(27.8)$ & $417(100)$ \\
\hline \multicolumn{10}{|l|}{ Gender } \\
\hline Female & $8(11.6)$ & $1(1.5)$ & $11(15.6)$ & $13(18.8)$ & - & $13(18.8)$ & $2(2.9)$ & $21(30.4)$ & $69(100)$ \\
\hline Male & $83(24.0)$ & $41(11.8)$ & $47(13.6)$ & 39 (11.3) & $17(5.2)$ & $13(3.8)$ & $11(2.9)$ & $95(27.5)$ & $346(100)$ \\
\hline Unknown & - & 1 & - & - & - & - & 1 & - & $2(100)$ \\
\hline All & $91(21.8)$ & $43(10.3)$ & $58(13.9)$ & $52(12.5)$ & $17(4.1)$ & $26(6.2)$ & $14(3.4)$ & $116(27.8)$ & $417(100)$ \\
\hline
\end{tabular}

Gender data $-\chi^{2}=38.06, \mathrm{df}=7, \mathrm{p}$ value $=<0.001$

${ }^{\star}$ Other less common causes, including 16 unknown; ftoy (4), domestic chemicals (1), stick (1), glass (1), other (3); $\ddagger$ toy (7), stone or metal missile (7), stick (4), air gun (3), glass (3) etc.

Table 4 Activity or object causing injury

\begin{tabular}{|c|c|c|c|}
\hline \multicolumn{2}{|l|}{ Activity or object } & No of cases & $(\%)$ \\
\hline \multicolumn{4}{|l|}{ Tools/machinery use at } \\
\hline Hammer/nails & $5(1.2 \%)$ & 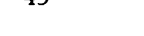 & $(10.0)$ \\
\hline \multicolumn{4}{|l|}{ Tools/machinery use at } \\
\hline home: & & 58 & (13.9) \\
\hline Kitchen tools & $7(1.7 \%)$ & & \\
\hline Garage tools & $25(6.0 \%)$ & & \\
\hline Garden tools & $19(4.6)$ & & \\
\hline Other tools at home & $7(1.7 \%)$ & & \\
\hline Assault & & 91 & $(21.8)$ \\
\hline \multicolumn{2}{|l|}{ Sport: } & 52 & (12.5) \\
\hline Bat/other equipment & $30(7.2 \%)$ & & \\
\hline Opponent & $13(3.1 \%)$ & & \\
\hline Squash ball & $4(0.96 \%)$ & & \\
\hline Football & $2(0.48 \%)$ & & \\
\hline Other ball & $3(0.72 \%)$ & & \\
\hline Fall & & 26 & $(6.2)$ \\
\hline Chemicals at work & & 18 & (4.3) \\
\hline Road traffic accident & & 13 & (3.1) \\
\hline Toy & & 12 & $(2.9)$ \\
\hline Broken glass & & 11 & $(2.6)$ \\
\hline Stck/branch & & 7 & (1.7) \\
\hline \multicolumn{4}{|l|}{ Fishing } \\
\hline hook/weight/rod & & 7 & $(1.7)$ \\
\hline Domestic chemicals & & 6 & (1.4) \\
\hline \multicolumn{2}{|l|}{ Gun accident: } & 6 & (1.4) \\
\hline Airgun & $4(0.96 \%)$ & & \\
\hline Starting pistol & $1(0.24 \%)$ & & \\
\hline Firearm (police) & $1(0.24 \%)$ & & \\
\hline \multicolumn{2}{|l|}{ Stone missile } & 5 & $(1.2)$ \\
\hline \multicolumn{2}{|l|}{ Metal missile } & 4 & $(1.0)$ \\
\hline \multicolumn{2}{|l|}{ Wire/paper clip } & 4 & $(1.0)$ \\
\hline \multicolumn{2}{|l|}{ Finger/hand } & 3 & $(0.7)$ \\
\hline \multicolumn{2}{|l|}{ Exploding bottle } & 3 & $(0.7)$ \\
\hline \multicolumn{2}{|l|}{ Pencil } & 2 & $(0.5)$ \\
\hline \multicolumn{2}{|l|}{ Champagne cork } & 1 & $(0.2)$ \\
\hline \multicolumn{2}{|l|}{ Dog (at home) } & 1 & $(0.2)$ \\
\hline \multicolumn{2}{|l|}{ Other causes } & 28 & (6.7) \\
\hline \multicolumn{4}{|l|}{ Unknown/ not } \\
\hline \multicolumn{2}{|l|}{ recorded } & 16 & (3.8) \\
\hline Total & & 417 & \\
\hline
\end{tabular}

patient services at the time of the study participated. Four hundred and twenty eight admissions for ocular trauma were reported during the study period. No further information was received on 11 patients, leaving data from a total of 417 patients for further analysis.

The age and sex distribution of patients admitted with ocular injury is shown in the figure. An excess of males is seen at all ages except the oldest age group of 75 years and over. Males accounted for $83 \%$ of all admissions and females $17 \%$.

The profiles of the injury characteristics - type, place, and cause of injury - in relation to age group and sex are presented in tables 1 to 3 .
TYPE OF INJURY

Overall, the main types of injury (in decreasing order of frequency) were : blunt $54.4 \%$ $(n=227)$, penetrating injury without an intra ocular foreign body (IOFB) $22.3 \% \quad(n=93)$, penetrating injury with an IOFB $7.2 \%(n=30)$, chemical burn $6.5 \%(n=27)$, and physical burn $1 \%(n=4)$. This pattern was consistently seen across all age groups (table 1). However, penetrating injuries with IOFB and chemical burns were notable by their excess frequency in males (table 1).

Bilateral ocular injury occurred in only $6 \%$ $(n=25)$ of patients. Over half of these patients $(52 \%, \mathrm{n}=13)$ had sustained a chemical injury, $24 \% \quad(n=6)$ had blunt trauma, $4 \% \quad(n=1)$ had a penetrating injury, while the remainder had some other, unspecified type of eye injury. On hospital admission, $13.4 \% \quad(n=56)$ of patients had an associated injury. These included facial injury in $7.9 \% \quad(n=33)$, head injury in $1 \%$ $(n=4)$, limb injury in $1.4 \% \quad(n=6)$, and $3.1 \%$ $(n=13)$ with some "other" less common non-ocular injury. These "other" injuries included fractured ribs, haemothorax, laryngeal oedema, facial lacerations, and generalised bruising.

PLACE OF INJURY

Table 2 shows the relative frequency distributions of place of injury in relation to age group and sex. The most common place for an injury to occur was in the home, accounting for $30.2 \% \quad(n=126)$ of all injuries. This was followed by the workplace $(19.6 \%, n=82)$, a

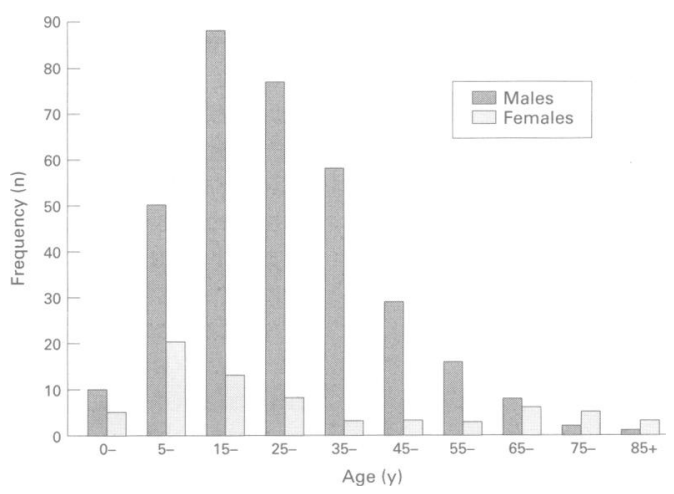

Figure 1 Distribution of patients admitted with ocular injury in relation to age and gender 
Table 5 Awareness of risk in relation to place of injury

\begin{tabular}{|c|c|c|c|c|c|}
\hline \multirow[b]{2}{*}{ Place of injury } & \multicolumn{5}{|c|}{ Awareness of risk } \\
\hline & Yes & No & Unknown & Total & $\%$ yes \\
\hline Home & 7 & 77 & 42 & 126 & 5.6 \\
\hline Sports/leisure place & 10 & 38 & 18 & 66 & 15.2 \\
\hline Work - industrial & 25 & 13 & 13 & 51 & 49.0 \\
\hline Work - commercial & 4 & 11 & 6 & 21 & 19.0 \\
\hline Work - agricultural & 3 & 4 & 3 & 10 & 30.0 \\
\hline Other & 2 & 22 & 18 & 42 & 4.8 \\
\hline Pavement/street & - & 17 & 21 & 38 & - \\
\hline School & - & 11 & 5 & 16 & - \\
\hline $\mathrm{Car}+$ seat belt & 1 & 1 & 5 & 7 & 14.3 \\
\hline Car - no seat belt & 1 & 1 & 2 & 4 & 25.0 \\
\hline Motorbike + helmet & 2 & - & 1 & 3 & 66.7 \\
\hline Bicycle - no helmet & - & 1 & - & 1 & - \\
\hline Not recorded & - & 5 & 16 & 21 & - \\
\hline Unknown & - & 1 & 10 & 11 & - \\
\hline All places & 55 & 202 & 160 & 417 & 13.2 \\
\hline
\end{tabular}

sports or leisure facility $(15.8 \%, \mathrm{n}=66)$, and on the pavement or street $(9.1 \%, n=38)$. Over half the injuries occurring in the workplace took place in an industrial setting $(n=51)$. Very few injuries took place in the $\operatorname{car}(2.7 \%, \mathrm{n}=11)$.

The home was the single most frequent place for an injury to take place in the 0 to 15 year $(50.5 \%, n=47 / 93)$ and the 65 years and older age groups $(60 \%, n=15 / 25)$. Although the home remained an important location in the intermediate age groups, this position was shared with the workplace, with $25 \%$ and $28 \%$ of injuries in the 16 to 24 year and 25 to 64 year age groups respectively, taking place there.

The distribution of place of injury is significantly different for males and females $\left(\chi^{2}=30.58, \mathrm{df}=10, \mathrm{p}\right.$ value $\left.=<0.001\right)$. Overall, males were notably more likely to sustain an injury in the workplace, with females being twice as likely to have sustained an injury at home, and both sexes being about equally at risk in a sports/leisure facility (table 2).

Blunt injuries were the most frequent type of injury occurring in the home $(54 \%, \mathrm{n}=68$ / $126)$, school $(68.8 \%, n=11 / 16)$, a sports or leisure facility $(80.3 \%, n=53 / 66)$, on the pavement $(68.4 \%, n=26 / 38)$, in a commercial workplace $(42.9 \%, \mathrm{n}=9 / 21)$, and in an agricultural workplace $(50 \%, n=5 / 10)$. Penetrating injuries most frequently occurred in an agricultural $(50 \%, n=5 / 10)$ or industrial workplace $(41.2 \%, \mathrm{n}=21 / 51)$, in the car or on a motorbicycle $(42.9 \%, \mathrm{n}=6 / 14)$, and in the home $(34.9 \%, \mathrm{n}=44 / 126)$.

CAUSE OF INJURY

The main causes of injury are shown by age and sex in table 3, with a full description

Table 6 First aid in relation to place of injury

\begin{tabular}{|c|c|c|c|c|c|}
\hline \multirow[b]{2}{*}{ Place of injury } & \multirow[b]{2}{*}{ Total no of cases } & \multicolumn{2}{|c|}{ First aid available } & \multicolumn{2}{|c|}{ First aid given * } \\
\hline & & No & $(\%)$ & No & $(\%)$ \\
\hline Home & 126 & 9 & -7.1 & 9 & $(100)$ \\
\hline Sports/leisure place & 66 & 17 & -25.8 & 9 & (52.9) \\
\hline Work - industrial & 51 & 26 & -51 & 16 & $(61.5)$ \\
\hline Work - commercial & 21 & 6 & -28.6 & 3 & (50) \\
\hline Work - agricultural & 10 & 1 & -10 & 1 & $(100)$ \\
\hline School & 16 & 9 & -56.3 & 3 & (33.3) \\
\hline Car & 11 & 3 & -27.3 & 3 & $(100)$ \\
\hline Pavement/street & 38 & 3 & -7.9 & 3 & $(100)$ \\
\hline Other/unknown & 78 & 10 & -12.8 & 10 & $(100)$ \\
\hline All places & 417 & 84 & -20.1 & 57 & (67.9) \\
\hline
\end{tabular}

* Percentage of first aid available provided in table 4 . Tools or machinery, either at work or in the home, were the most common causes of injury, accounting for about a quarter of all injuries $(24.2 \%, \mathrm{n}=101)$. These were followed by assault which was responsible for about a fifth of injuries $(21.8 \%, n=91)$. Sports related activities (from opponent, equipment racquet, ball etc, or contact sport) were responsible for $12.5 \%(n=52)$ of injuries. Falls accounted for $6.2 \%(n=26)$, and chemicals (domestic or occupational) for $5.8 \%(n=24)$ of injuries in patients admitted.

Although over half the injuries $(53.8 \%$, $\mathrm{n}=50$ ) in the younger age groups 0 to 15 years were collectively caused by a variety of entities, the most frequent single causes were assault $(14 \%, \mathrm{n}=13)$ and sports related activities $(16.1 \%, n=15)$. Tools or machinery (at work and at home) were important causes of injury in the 16 to 24 and 25 to 65 year age group, followed by assault and sports related activities. Among patients of 65 years and older, falls were the single most frequent cause of injury, accounting for $44 \%(n=11)$ of injuries, followed by tools or machinery in the home, causing $20 \%(n=5)$ of injuries (table 3$)$.

The overall distribution of cause of injury is significantly different for males and females $\left(\chi^{2}=38.055, \mathrm{df}=7, \mathrm{p}\right.$ value $\left.=<0.001\right)$. Males were more likely to sustain an injury from tools, machinery, or chemicals at work and were twice as likely to have an injury caused by an assault. Females were about five times more likely to sustain an injury from a fall (table 3).

One third $(31 \%, n=25)$ of assaults took place on the pavement/street and about one fifth $(19.8 \%, n=16)$ in a sports or leisure facility. Some $62.5 \%$ of falls occurred at home and a quarter $(25 \%)$ on the street. Altogether $73 \%$ of sports related activities causing injury took place in a sports or leisure facility, while about $12 \%$ occurred at home and $6 \%$ at school

AWARENESS OF RISK AND SAFETY

As shown in table 5, this information was available for $62 \%$ of patients. Only $13.2 \% \quad(n=55 /$ 417) of all patients were aware of any risk of injury at the time it took place. Awareness was greatest amongst patients who sustained an injury in the workplace: $49 \%(n=25 / 51)$ industrial, $30 \%$ agricultural $(n=3 / 10), 19 \%$ commercial workplace $(n=4 / 21)$. Only $15.2 \% \quad(n=10 /$ 66) of patients were aware of a risk of injury occurring in a sports facility and only $5.6 \%(n=7 / 126)$ while pursuing activities in the home.

There were 74 cases where protective eye wear was ascertained to have been applicable from the patient, with less than half of these $(47 \%, n=35)$ being aware of any risk of injury associated with the activity they were pursuing. When applicable, protective eye wear was available for only $48.6 \%(n=36 / 74)$ of patients, with only a fifth $(19.4 \%, n=7 / 36)$ of them wearing it.

First aid was available for a fifth of all injuries $(20.1 \%, \mathrm{n}=84)$ and was administered in two thirds of these cases $(67.9 \%, n=57)$. 
Availability ranged from $56.3 \%$ in schools to $7.1 \%$ in the home. When first aid was available it was generally administered, but in schools only one third of patients received it $(33.3 \%$, $n=3 / 9)$, while $50 \%$ of patients $(n=3 / 6)$ received it in a commercial workplace, $61.5 \% \quad(n=16 /$ 26 ) in an industrial workplace, and $52.9 \%$ $(n=9 / 17)$ in a sports or leisure facility (table 6$)$.

\section{Discussion}

This prospective, population based study has provided data on the current pattern of serious ocular injuries in patients admitted to hospital under the care of a consultant ophthalmologist. Given that the age structures of the populations of England, Wales, and Northern Ireland $^{13}$ are similar to Scotland(personal communication, Information and Statistics Division, National Health Service in Scotland, Edinburgh), these findings may be considered relevant to the whole of the UK.

Ocular trauma is predominantly uni-ocular and localised to the eye. The overall pattern of serious injuries observed regarding age group, cause, and type of injury is consistent with previous reports, ${ }^{1} 461014-16$ the exception being the proportion of road traffic accidents causing injury. Only $3.4 \%$ of all injuries in this study were a result of a road traffic accident and this probably reflects the steadily declining trend observed in this country since the introduction of legislation in 1983 for the compulsory wearing of seat belts. ${ }^{1718}$ Although tools and machinery are still major causes of moderate to severe eye injuries, assaults are now equally as important. This worrying trend reflects the current pattern of assaults becoming increasingly important causes of not only serious ocular trauma, ${ }^{19}{ }^{20}$ but also of life threatening body trauma.

Prevention and safety measures have traditionally focused on the workplace, and this clearly still remains an important area. In recent times, preventive strategies have expanded to include sports and related activities, as these have become recognised as important factors associated with injury. ${ }^{17-9}$ The present data probably reflect this, as these now take second and third place respectively, with the home now being the commonest place $(30 \%)$ for injuries of sufficient severity to warrant admission to hospital.

Previous reports from Malawi and Israel have recognised the home as an important location for the occurrence of serious eye injuries. ${ }^{21}{ }^{22}$ However, to our knowledge, this is the first time that the home has been reported or recognised as being the most frequent place for moderate to severe ocular injuries to take place (at all ages), within the UK. Given this, it is possibly one of the least likely locations for individuals to be aware of any risk of an eye injury occurring. The use of domestic tools or machinery (with increasing frequency with age) and falls among the elderly are the most commonly identifiable causes of injury in the home. We estimate that $52 \%$ of all blinding injuries occur in the home. ${ }^{12}$

The home has long been recognised as an important location for other types of injury and accidents(fatal and non-fatal). In 1988 it was estimated that 2.3 million non-fatal accidents (of all types) took place there. The overall rate for all "home" accident cases receiving medical treatment(general practitioner or hospital) was estimated to be 56 per 1000 per year, accounting for a third of all accidents treated by hospitals. The main risk factor for an accident at home is age - the very young and the elderly are at greatest risk. ${ }^{23}$ In the present study, $50.5 \%$ of injuries in the $0-15$ year age group and $60 \%$ of injuries in the 65 years and over age group took place at home, and home was the single most frequent place for an eye injury to occur in these age groups.

It is also estimated that $60 \%$ of all accidents for which medical care is sought in the 65 years and older age group are from falls. ${ }^{24}$ In this study $62 \%$ of falls resulting in serious eye injury took place in the home, and accounted for the single most frequent cause of injury $(44 \%)$ in people 65 years of age and older.

In circumstances where protective eye wear may have been applicable, it seems that not only is it not readily available for use, but there still remain barriers to its use. This has been reported previously and the main reasons for not wearing protective eye equipment were as follows: uncomfortable, badly fitting, cumbersome, and creating problems with seeing adequately to perform the task in question, coupled with an element of risk taking behaviour in susceptible groups. ${ }^{1}$

These findings have implications for health and safety strategies for the prevention of serious eye injuries. These should now be extended to include the home as well as the workplace and sports and leisure facilities These strategies should aim to raise awareness of the hazards associated with particular activities(eg use of domestic tools and machinery); and increase the availability and use of safety measures(including environmental modifications and specific protective eye wear), particularly in the home.

If health and safety strategies are to be effective in preventing injury, it is essential that a collaborative, multidisciplinary approach exists between interested parties, fostering constructive working relationships between health care professionals, local authorities, voluntary organisations, industry and commerce, regional home safety councils etc. Such initiatives are difficult to establish and maintain, particularly for the prevention of specific types of injury. If these are to be developed, then the current climate is particularly supportive since the Government's strategy for health, The Health of the Nation, has endorsed the development of healthy alliances and multidisciplinary relationships for this purpose. ${ }^{24}$

Accident prevention has been identified as one of the key areas of national priority for the improvement and maintenance of health in the population. ${ }^{24}$ With regard to accidents, this strategy is concerned with reducing avoidable mortality from accidental injury, particularly in the young and the elderly and from accidents occurring at home. These target groups also 
include those at risk of serious ocular trauma. If health care professionals currently involved in implementing the national accident prevention strategy are made aware of this, then it is possible that some serious eye injuries may also be prevented in the process, thereby reducing avoidable visual morbidity (visual impairment and disability) and producing an unexpected, yet desirable outcome.

The authors thank all the local coordinators and ophthalmologists in Scotland and their secretarial staff, without whose support and contribution this study would not have been possible. Miss Kate Bullock and Miss Marisa Tomlinson at the Royal College of Ophthalmologists and Ms Lynda Rose at Ninewells Hospital, Dundee.

This study was supported by a grant from the Scottish Home and Health Office, Clinical Resources and Audit Group. Grant Number CA 91/9. PD was supported by Core Audit Funding from the Department of Health for the Royal College of Ophthalmologists, London, for the conduction of this study.

1 MacEwen CJ. Eye injuries : A prospective survey of 5671 cases. Br $\mathcal{F}$ Ophthalmol 1989;73:888-94.

2 Chiapella AP, Rosenthal AR. One year in an eye casualty clinic. Br F Ophthalmol 1985;69:865-870.

3 Vernon SA. Analysis of all new cases seen in a busy regional centre of an ophthalmic casualty department during a 24 centre of an ophthalmic casualty department

4 Bhopal RS, Parkin DW, Gillie RF, Han KH. Pattern of ophthalmological accidents and emergencies presenting to thalmological accidents and emergencies presenting to

hospitals. F Epidemiol Community Health 1993;47:382-287.
5 Jones NP, Hayward JM, Khaw PT, Claoue CMP, Elkington AR. Function of an ophthalmic accident and emergency department: Results of a six month survey. BMF 1986;292:188-90.

6 Karlson TA, Klein BEK. The incidence of acute hospital treated eye injuries. Arch Ophthalmol 1986;104:1473 1476.

7 Canavan YM, O'Flaherty MJ, Archer DB, Elwood JH. A 10 year survey of injuries in Northern Ireland 1967-76. Br $\mathcal{F}$ Ophthalmol 1980;64:618-25.
8 Jones NP, Griffith GAP. Eye injuries at work : A prospective population-based survey within the chemical industry. Eye population-based

9 Danneberg AL, Parver LM, Brechner RJ, Khoo L. Penetrating eye injuries in the work place. The national eye trauma system registry. Arch Ophthalmol 1992;110:843-848.

10 Danneberg AL, Parver LM, Fowler CJ. Penetrating eye injuries related to assault. The national eye trauma system registry. Arch Ophthalmol 1992;110:849-852.

11 The Department of Health. The health of the nation: A strategy for health in England. London: HMSO, 1992.

12 Desai, P, MacEwen CJ, Baines P, Minassian DC. Incidence of cases of ocular trauma admitted to hospital and incidence of blinding outcome. Br $\mathcal{J}$ Ophthalmol 1996; 80:1-5.

13 Central Statistics Office. Annual abstract of statistics 1992. No 28. London: HMSO, 1992.

14 Tielsch JM, Parver LM, Shankar B. Time trends in the incidence of hospitalized ocular trauma. Arch Ophthalmol 1989;107:519-523.

15 Klopfer J, Tielsch JM. Ocular trauma in the United States. Eye injuries resulting in hospitalization, 1984 through 1987. Arch Ophthalmol 1992;110:838-842.

16 Sykes WN. A 10 year survey of penetrating eye injuries in Gwent, 1976-85. Br f Ophthalmol 1988;72:607-611.

17 Hall NF, Denning AN, Elkington AR, Cooper PJ. The eye and the seat belt in Wessex. Br f Ophthalmol 1985;69:317319 .

18 Cole MD, Clearkin L, Dabbs T, Smerdon D. The seat belt law and after. $B r \mathcal{F}$ Ophthalmol 1987;71:436-440.

19 Liggett PE, Pince KJ, Barlow W, Ragen M, Ryan SJ. Ocular trauma in an urban population. Ophthalmology 1990; 97:581-584.

20 Zagelbaum BM, Totsanoski JR, Kerner DJ, Hersh PS. Urban eye trauma. A one year prospective study. Ophthalmology 1993;100:851-856.

21 Ilsar M, Chirambo M, Belkin M. Ocular injuries in Malawi. Br f Ophthalmol 1982;66:145-148.

22 Koval RK, Teller J, Belkin M, Romem M, Yanko L, Savir H. The Israeli Ocular Injuries Study. A nationwide collaborative study. Arch Ophthalmol 1988;106:776-780

23 Home and leisure accident research. 1989 Data. Thirteenth annual report of the Home Accident Surveillance System. Consumer Safety Unit, The Department of Enterprise (DTI).London: DTI, 199?.

24 Department of Health. Health of the nation key area handbook: Accidents. London: HMSO, 1991. 